\title{
Providing Interdisciplinary Services to At-Risk Families to Prevent the Placement of Children In Foster Care
}

\author{
By Deborah J. Weimer
}

\begin{abstract}
Grandparents need support to take on the responsibility of children whose parents cannot care for them due to drug addiction, mental health issues, HIV illness, or other health problems. Without support and assistance, these families and children are likely to end up enmeshed in the already overburdened child abuse and neglect system. The University of Maryland has created a model program providing social work and legal services to at-risk grandparent families to help avoid the unnecessary placement of these children in foster care. In this new program, student attorneys and student social workers worked with the grandparent client to help stabilize the family, providing representation or advice on housing, public benefits, custody, and school-related issues. Joint education of student attorneys and student social workers in a clinical experience enhances their understanding of their roles and those of the other profession and prepares them for a more thoughtful and informed approach to family law, child welfare cases, and at-risk children.
\end{abstract}

\section{INTRODUCTION}

Developing opportunities for truly interdisciplinary practice between social workers and lawyers offers great benefits nor only to the clients served, but also to the professionals delivering the service. Working with social workers to assess a family's needs and deliver services that contribute to the welfare and stability of the family is an alternative to the current model of legal services delivery. In fact, the stated goals and aspirations of the social work profession are in many ways more compatible with the goals

Deborah J. Weimer is a Professor in the Clinical Law Program of the University of Maryland School of Law in Baltimore. She has directed the AIDS Litigation and Counseling Clinic for 20 years. She created an Interdisciplinary Practice with Grandparent Families Clinic to work with the Maryland School of Social Work on a joint service/research project. Correspondence: dweimer@law.umaryland.edu 
of lawyers for poor people than are the goals of the legal profession as a whole. As Jane Aiken and Stephen Wizner point out, the social work profession identifies working for social justice as an ethical mandate. ${ }^{1}$

The predominant model of legal services practice for the poor tends to serve many clients on one or more legal issue, often with no lasting impact on the family's wellbeing. The attorney may be able to prevent an eviction this month, but the family is back six months later with another poverty-related issue. In addition, of course, there are many more poor clients than legal services funded at current levels can serve. That model soon leads to attorney burnout, as attorneys serve clients victimized by poverty over and over in similar cases, but see no real change in the circumstances that brought the clients to the attorney in the first place. ${ }^{2}$

A history of distrust between attorneys and social workers and differing ethical rules has discouraged widespread collaboration between attorneys and social workers working with poor clients until relatively recently. ${ }^{3}$ Even today, the primary model of lawyers and social workers working together is one where one or two social workers are brought in to a legal services office to assist with aspects of the legal cases. There is generally no attempt to take a truly interdisciplinary approach to problem solving for poor families. This model may be appropriate in some instances, but it tends to undervalue and under-utilize the skills a social worker could otherwise bring to a client/family, and to advocacy for the poor more generally. The model often does not address the underlying problems that may have led to the legal issue in the first place. $^{4}$

1 Jane Aiken \& Steve Wisner, Promoting Justice Tbrough Interdisciplinary Teaching Practice and Scholarship Law as Social Work, 11 WASH. U.L.J. \& POL'Y 63 (2003).

2 Stephen Wexler, Practicing Law for Poor People, 79 YALE L.J. 1049 (1970).

3 Perhaps one of the earliest entities to establish this kind of practice was the Institute on Law and Rights of Older Adults at the Brookdale Center on Aging of Hunter College, founded in fall 1977. S. Aaronson, A. Koski, N. O'Brien, N. Polimeni, E. Rosenzweig, \& D. Sacks, The Successful Marriage of Law and Social Work, Clearinghouse Review 450, Summer 1989.

4 In the 1930s, New Deal poverty programs put great emphasis on the role of professional social workers in assisting families and administering benefits. Simon Williams, Papers from the Yale Law Journal Symposium on the Legacy of the New Deal: Problems and Possibilities in the Administrative State, 92 YALE L.J., 1190, 1214 ( June 1983).

In the 1960s and 1970s, this model of administration of welfare benefits fell out of favor. Many felt that having social workers involved in the administration of benefits led to invasion of privacy and inappropriate judgmental decisions. The system was dramatically overturned and new rules put in place to minimize the need to know a family and exercise judgment. Formal rules about benefit eligibility were put in place, and workers became technicians charged with carrying out the rules.

Although some local legal aid programs existed, federal funding for legal services for the poor became available for the first time as part of the War on Poverty with the passage of amendments to the Economic Opportunity Act in 1966. This Act was premised on the idea that local community action agencies (CAAs) would decide how to address poverty on the community level. In practice, most CAAs did not fund legal services, at least in part due to concern that lawyers oppose CAA goals.

Because of this, and also because of the American Bar Association's insistence that the legal services program should be entirely free of lay control, locally, regionally and nationally, funding for legal services programs was earmarked separately. Alan W. Houseman \& Linda E. Perle, Securing Equal Justice For All: A Brief History of Civil Legal Assistance in the United States, p. 7-8 (Center for Law and Social Policy, Nov. 2003). This history thus effectively ensured that in most places a newly funded poverty program would not be working collaboratively with social worker and community representatives who in theory shared the goal of eradicating poverty. 
The University of Maryland Law School Clinical Program has had a social work component for 17 years. It follows the model of social workers coming in to assist with legal cases, and in its way has been very successful. Student social workers are asked to step in to help clients solve various problems, e.g., making a plan for children in the event of the parent's disability or death, accessing drug treatment for a client facing criminal charges, etc.

In Fall 2003, in addition to the program described above, the University of Maryland initiated a fresh approach to collaboration with social workers in a new project which has proved innovative and exciting. This new project, Grandparents Family Connections, involved interdisciplinary collaboration among the Schools of Social Work, Law and Nursing at the University. ${ }^{5}$ From the beginning, we agreed on an interdisciplinary approach where no profession's values predominate, and where we strive to work toward consensus on our approach to each case.

The project was designed to serve the needs of at-risk grandparent families, with the goal of providing sufficient support and services to these families to help avoid the removal of the grandchildren by DSS placement in foster care. ${ }^{6}$ Goals are developed in partnership with each family. A service plan is put together with the client's full participation. The primary focus in delivery of legal services is identifying what will best serve the stability of the family and welfare of the children. ${ }^{7}$

The goal is not just to assist the families with today's concrete needs, which are many, but also to work toward empowering family members to be better able to advocate for themselves in the future. In addition, the project has a research component to assess the effectiveness of this interdisciplinary service on family well-being. The results have been encouraging, as described below. And an important benefit of working as equal partners with our collaborators has been the mutual respect and understanding that has developed between social work students and law students.

This article will briefly describe the rules that have been perceived as barriers to effective interdisciplinary practice, including rules about lawyer independence, identifying the client, and mandated reporting of child abuse and neglect. The article identifies

Proposals for interdisciplinary practice were rejected because of an objection to the apparent subordination of lawyers to other professions, but also because of the focus on intensive services to families. The concern was the proposal would simply not serve large enough numbers of clients. Marc Feldman, Political Lessons: Legal Services for the Poor, 83 GEO. L.J. 1529 (April 1995).

5 The original structure for Grandparent Family Connections included a healthcare component. We had a partner from the School of Nursing to help grandparents and grandchildren with unmet healthcare needs. Unfortunately, the resources under the grant were insufficient to sustain this aspect of the original plan.

6 This project was funded by a five-year grant from the Children's Bureau to research what type of intervention would be most effective in supporting at-risk grandparent families. One of the key questions to be addressed was would the addition of legal and healthcare services to social work services for families significantly affect the outcome for these families? The first year was spent setting up the project's infrastructure, which included an extensive system to collect data about services provided and outcomes.

7 To qualify for services in this program, a family had to be experiencing difficulty in meeting basic needs. The most common reasons families were referred (and half of the families were self-referred) were children with special needs that were not being met in school, acting-out behavior in school, and unmet health needs of grandparents. Difficulty in accessing public benefits was another major issue impacting these families. 
the importance of advance planning in structuring a truly interdisciplinary practice and anticipating and addressing ethical issues. And it describes the benefits, to clients as well as social work and law students, of engaging in this kind of supportive interdisciplinary practice.

\section{INTERDISCIPLINARY PRACTICE FOR GRANDPARENT FAMILIES}

In 2001, the University of Maryland School of Social Work's Center for Families approached UM's Law Clinic about collaborating in a small pilot project serving grandparent families. That pilot involved collaboration between an experienced social worker and student attorneys and their supervising attorney. After this successful beginning, the partners agreed to initiate a more ambitious collaboration. The School of Social Work received a grant from the Children's Bureau to replicate its successful work with grandparent caregivers in at-risk families. The project was set up to compare the effectiveness of several different models in order to identify which model most effectively prevented the necessity of foster care placement for at-risk grandchildren.

The interdisciplinary model involved the most intensive services, including legal and medical as well as social work services. The interdisciplinary partners included the University of Maryland Law Clinic (the Interdisciplinary Practice with Grandparent Families Clinic), ${ }^{8}$ Family Connections (an existing project of the UM School of Social Work Center for Families ${ }^{9}$ ), and the School of Nursing.

Family Connections was created in 1997 by the Center for Families to assist families who were struggling to meet the basic needs of their children. The program was funded by a grant from the Children's Bureau to conduct a research and service project assessing the effectiveness of interventions with at-risk families. The goals of the original design were to provide a variety of services to parents and children that would help decrease risk factors (e.g., parental depression, stress, substance abuse) and help increase protective factors (e.g., parenting attitudes, attitudes toward change, social support). The data collected as a result of the first five-year project showed that the social work

8 Our interest in working with grandparent families grew out of our longstanding work with relative caregivers in the AIDS Legal Clinic. The AIDS Legal Clinic was created in 1987 to provide civil legal services to individuals and families impacted by the AIDS epidemic. We represented clients in discrimination claims and public benefits appeals, as well as family law cases. We advocated for standby guardianship legislation so that single parents with HIV illness could authorize someone to assist them in caring for their children without having to give up their right to custody. We also assisted family members, including many grandparents, in seeking custody after the parent had died. The social work services available in our clinic program were helpful, but were tied to the needs of the legal cases. Social work services generally had to be connected to a legal issue and ended when the legal case ended. Our approach to working with families was to work with parents and other family members to try to achieve the best possible outcome for children, which fit well with the Family Connections model.

9 The Center for Families began as a partnership between the School of Social Work and the Department of Pediatrics, at the University of Maryland School of Medicine. The Center for Families develops innovative best practice interventions, helps bridge the gap between research and practice, and educates professionals to address more effectively the problems of child maltreatment and associated issues (substance abuse, depression, neighborhood violence, poverty, etc.). 
intervention had been successful in reducing risk factors, particularly parental depression, and increasing protective factors, namely, parents' sense of competence, family functioning, and support. Family Connections has been recognized by the Children's Bureau as being effective in reducing child neglect, and the program is being replicated around the country. Grandparent Family Connections was created to assess the effectiveness of similar interventions with at-risk grandparent families.

A primary goal of our social worker partners is client empowerment. By supporting and encouraging the client to tackle difficult issues, they hope to leave the client in a stronger place when the relationship ends. The social worker may have opinions about what steps the client should take, but the worker's job is to meet the client where she is and develop goals together, not to push her in a direction she does not want to go. This approach was consistent with our belief in client-centered decision making. ${ }^{10}$

Family Connections trains social workers to use practice principles that will be most effective in supporting at-risk families. These principles include developing a partnership with the family to empower the caregiver to address issues after the social worker intervention has ended. One way to achieve this partnership is by identifying and emphasizing the caregiver's strengths and helping her to build on those qualities, a fundamental component of the Family Connections approach.

Another way to empower the caregiver is to connect her with others in the community who may be facing similar challenges. The families help support each other. As a result, another piece of the program is organizing events for families to get together. This gives caregivers an opportunity to meet other grandparents and reduce the sense of isolation that sometimes occurs when grandparents care for grandchildren.

In addition, parents and grandparents can see that their struggles are not just their individual problems, but stem at least in part from structural problems in society--e.g., underfunded and inadequate schools, lack of employment opportunities in the inner city, the epidemic of drug use, and lack of affordable housing.

Family Connections and the AIDS Legal Clinic share the goal of involving clients as advocates for themselves and the communities in which they live. Although it was not the primary focus of our joint work in the initial Grandparent Family Connections grant, we are planning to work together with the grandparent community on advocacy about the issues identified. ${ }^{11}$

\section{Structure and Day-to-Day Functioning of GFC Project}

Because a primary goal of this project is to help stabilize grandparent families, the first criterion was that the grandchildren must have been living with their grandparent

10 For example, in some cases, the social worker felt that the grandparent was ambivalent about having custody of grandchildren. In these situations, we would still meet with the grandparent to be sure that she was aware of the potential benefits and downsides of filing for custody, and understood that obtaining custody was not necessarily a permanent arrangement, unlike adoption. In these situations, the attorney would counsel the client, as would the social worker. The decision was always ultimately left to the client.

11 Family Connections has received funding support to develop a housing model for grandparent families. They have held a series of meetings to gather input from the affected community and are visiting models in other states to assess what would work best for families in Baltimore. 
for at least six months. ${ }^{12}$ In addition, the family must be struggling with issues that put the children at risk for foster care placement. ${ }^{13}$ Possible risk factors include unemployment or over-employment, substandard housing, children's acting-out behavior, unmet health or mental health needs of grandparents or children, and alcohol or drug abuse issues.

A social worker meets first with the grandparent to do a family assessment and also to ascertain if there are any crisis situations that need emergency attention from legal or medical staff-e.g., threatened eviction or severe health risk. If so, an immediate referral to legal or nursing staff is made. If not, the nurse meets next with the family to do an overall health assessment of grandparent and grandchildren.

At the first meeting, social work staff also discusses with the client the collaborative nature of the practice and the sharing of information among social, legal, and nursing team members. The client is asked to sign a consent form agreeing to this sharing of information.

Then the social work student communicates to the legal staff his or her initial assessment, including any legal issues the client may need assistance with. The student attorney interviews the client about her goals and legal needs, does any necessary research, and generally will bring this information to the team meeting where social work, law, and nursing are each represented. The student attorney informs the team of his or her assessment of the applicable law and the client's options, and discussion of the pros and cons of these options takes place.

Shortly thereafter, the student attorney meets with the client about the options identified. Depending on the client's wishes and the subjects to be discussed, the social work student may also participate in the counseling session.

An overall service plan is prepared to address client goals which generally includes social work, legal, and health-related plans for action. Often there are overlapping responsibilities, requiring close coordination among the various service providers. The social work student meets with the client to review the service plan. If legal action is part of the plan, the student attorney meets separately with the client to sign a retainer which specifically describes the legal action to be taken and the limits of our representation. ${ }^{14}$

The Interdisciplinary Team also meets regularly, at least twice a month, to review progress in each case, discuss issues as they arise, make decisions about case management, etc.

12 Although the project was open to assisting grandparent-led families, the families in our joint work were exclusively led by grandmothers raising children on their own.

13 Gregory C. Smith \& Patrick Palmieri, Risk of Psychological Difficulties Among Cbildren Raised by Custodial Grandparents, 58 PsYCHIATRIC SERviCES, 1303 (October 2007).

14 Law students enroll in the Interdisciplinary Practice Clinic for two full semesters-fall and spring. Social work students are in placement with Family Connections for two semesters. A three-hour joint orientation for all participants takes place at the beginning of the first semester, giving students an overview of the goals of the project including both service and research. A description of the issues likely to be addressed by each discipline is provided, with case examples to illustrate. Potential conflicts in ethical rules, the importance of confidentiality and related case management issues are discussed. Additional interdisciplinary classes have addressed such topics as client engagement, client empowerment, endings with clients, dealing with cultural differences/barriers in working with clients. 
To achieve the goal of client empowerment, social work services are limited to a six-month period of working with each client, which is explained to the client in the beginning. The goal is to work intensively with the clients, address their priorities, and try to help them identify new ways of coping and advocating for themselves. The relationship is terminated before the client becomes dependent on the social worker for assistance.

Legal services often are not fully accomplished within this time frame. We followed through on whatever commitments have been made-e.g., representing clients in hearings regarding custody petitions filed, which often take place after the social work case has been closed.

In addition, we have identified systemic issues that we will address together or separately in the future. ${ }^{15}$

\section{Benefits and Challenges of Joint Practice for Clients/Families}

Offering combined services of lawyers and social workers unquestionably provides an excellent opportunity for many families to overcome obstacles to stability and safety for children. Examples of joint cases are described below.

The downsides are few, but they are important to note. In the GFC project, a few families did not follow through with services. In a couple of cases, it appeared that the grandparent simply was not comfortable with having weekly meetings with a social work student. For some families, intensive services are simply too invasive or too time-consuming.

In addition, offering such intensive services does limit the number of families who can be served. But if our theory is correct and these families are significantly more stable, better connected, and able to cope with future challenges because of this assistance, the project is more than cost effective in the long run.

\section{Community Outreach/Education}

As part of our outreach to the potential client community, three student attorneys who were working with GFC clients put together a workshop for grandparents about their legal rights and options when caring for grandchildren. The student attorneys conducted these workshops for grandparents at three elementary schools in Baltimore City in early 2006.

The students and the grandparents learned from each other in these workshops, and the students enjoyed the experience a great deal. The students learned about the challenges grandparents face outside the artificial constraints of the lawyer/client

15 For example, it has come to our attention through this joint work that indigent grandparents are being required to enter a work program to qualify for a TANF grant to help them care for their grandchildren. This is a clear violation of the Department of Social Services' own regulations on this subject (see COMAR 07.03.03.07(I)(4)(e). We plan to schedule a joint meeting with appropriate officials to request that they take steps to correct this local practice. Another concern that has repeatedly come up is the frequency with which families who have inherited real property that is already fully paid for lose this property because of their lack of understanding about tax laws. 
relationship. The workshops also benefited the grandparents who received information about their legal rights and options. Grandparents often did not realize that there was a custody option that would not terminate a parent's rights, which could be modified if a parent's circumstances change and they are able to step back into a parenting role. The grandparents also enjoyed sharing stories and learning from each other.

These workshops met the goal of client empowerment that we had rediscovered in our work with our social work partners. Although many grandparent caregivers need the support of an interdisciplinary practice, others simply need legal information to take steps they need to stabilize their families.

\section{CASE EXAMPLES}

Having Various Interdisciplinary Services Available at the Same Time Makes Real Progress Possible

Social workers bring to the table not only the ability to assist the family in meeting concrete needs (e.g., dealing with a threatened utilities cut-off, making sure the family has enough food to make it to the next payday), but also to help the family address more complex needs. For example, the social worker may identify and help the client address unmet health needs that interfere with her ability to function on a day-to-day basis. A grandparent who has moved in to care for her grandchildren may become socially isolated and overwhelmed by the needs of her grandchildren, often leading to depression. The social worker can help the grandparent identify steps to take to alleviate the depression.

In the meantime, the student attorney can work on other concrete needs. For example, often the family's housing is in poor condition-depending on the circumstances, a rent escrow action (withholding rent until the landlord makes appropriate repairs) may be in order. In many cases, the grandparent may need assistance in obtaining legal custody of the grandchildren. Obtaining custody is often necessary to avoid future problems-e.g., barriers to enrolling children in school, obtaining housing subsidy that takes children into account, etc.

\section{Case Example \#1}

This family was at risk of losing its bome because of a tax lien and threatened sale of the bouse. The grandmother bad inberited the bouse and did not understand the consequences of not paying property taxes. Despite the grandmotber's work as a day care provider, the family simply did not have the money to meet its expenses each month. The client bad long boped to find a better paying job, but found the obstacles to a job search overwbelming. After meeting with ber client on a regular basis for several weeks, the social work student belped the client achieve ber goal of finding a bigher paying job doing work she enjoyed. She began a new job at a flower shop, which was a good match for her interests. The social worker belped concretely, botb in providing transportation for the job search and in providing emotional support to the client that belped her believe that change was possible. 
In the meantime, the student attorney researched options to address the tax lien, and ultimately concluded that bankruptcy was the only viable option. However, the social worker was also exploring options to address the lien and successfully convinced a local bank to offer the client a mortgage. The client was pleased at the idea of being able to qualify for a mortgage to pay off the lien, but ultimately decided bankruptcy would be a safer, less expensive course of action.

The social worker also worked with the client to develop a budget and prioritize bills to be paid to belp the client avoid another financial crisis.

The partnership of student attorney and student social worker was critical in this case. Neither profession, working alone, would likely have successfully helped this client save her home. Without assistance in finding a better paying job, the client would have been unable to make the payment to the bankruptcy court each month. The social worker working alone probably would not have been able to advise the client about legal ways to protect her home or identified bankruptcy (Chapter 13) as a helpful option.

\section{Attorneys and Social Workers Bring Different Skills and Perspectives to Assisting Clients with Special-Needs Children}

One major role that social workers often play in our joint cases is helping the student attorneys achieve a deeper understanding of a child's special needs in a particular situation. The student attorney is then better able, perhaps in a situation involving an Individualized Education Plan (IEP), to counsel the grandparent about the child's needs and the options available.

Children and adolescents with special needs, especially poor inner-city children, tend to be misdiagnosed and prescribed medication after a short visit with a psychiatrist. Our social work partners have proved invaluable in being able to examine these diagnoses critically and to support grandparents where necessary in obtaining a second opinion and appropriate care.

Grandparents are often appropriately skeptical about their grandchildren's mental health diagnoses and sometimes refuse to administer medication. Social workers can connect families with mental health care providers and ensure that children are properly diagnosed and treated.

\section{Case Example \#2}

A grandmother caring for ber 7-year-old grandson, Justin, distrusted the school's recommendation that the child should be moved to another school with a program for emotionally disturbed children. Initially, we shared ber skepticism. Too many poor African-American boys in Baltimore bave been incorrectly labeled as emotionally disturbed and placed in inappropriate programs.

Justin had lost bis mother when she was 16 to a drug overdose, and bis fatber to a 10-year jail term. The family bome bad been lost in a fire. Justin bad been depressed and anxious for years and was acting out in violent ways in school. The school was worried about bis safety and that of bis classmates. He bad bad two psychiatric bospitalizations. He was a bright child, but he was not progressing academically. Nevertheless, his grandmother was adamant that the school should try barder to meet bis needs. 
The GFC social worker who bad been working with the family for several months had a good relationship with the grandmother and a clear understanding of the severity of the child's needs. She connected the grandmother to mental bealth services at the University of Maryland that could thoroughly evaluate Justin. He was found to be suffering from post traumatic stress disorder and severe depression, as well as ADHD. The social worker shared with the grandmother her opinion that the neighborbood school really could not meet the child's needs. He needed a school where staff was truly equipped to meet his emotional needs, and trained to bold bim therapeutically when bis emotions spun out of control. With the appropriate support to deal with bis emotional issues, Justin should be able to improve in bis school work. Eventually, be might be able to reintegrate into a regular class setting.

Our client agreed to the placement and after the initial adjustment period, the child's acting out decreased. He is able to participate in school and is making substantial progress academically.

We are in contact with the grandmother to determine when the child may be ready to return to a regular classroom and will advocate on bis bebalf at that time. We also assisted our client in appealing a denial of SSI benefits for her grandson. We were successful in obtaining these benefits after a bearing before an administrative law judge.

If we had not had a social work partner in this case, we might have continued to insist on our client's goal of inclusion in a regular classroom for her grandson, which most likely would have led to further violent behavior on his part and ultimare failure. Instead, because of the trusting relationship our client had developed with our social work partner, the client understood the child's need to be in a specialized program, and she was glad to work with the new school to see that her grandson received the emotional support and structure he needed.

\section{Attorney's Advocacy Plus Social Workers' Work With Family Result in Success for Children}

\section{Case Example \#3}

A client was having diffculty managing her twin boys, who had just entered kindergarten. They were running wild at school, refusing to stay in class, getting into fights with otber kids, and generally baving an extremely difficult time adjusting to school, despite the fact that they had been in pre-school. They were also acting out at bome, refusing to go to bed at nigbt, etc. The school called our client to come in almost every day to belp manage their behavior. There was great concern for their safety as well as for the safety of their classmates.

A case plan was developed with the client in which the student social worker would assist the client in working on ber skills in managing the boys' behavior at home. The student attorney and student social worker worked together with the school to determine what assessments might be appropriate to determine what was causing the boys' behavior. The social work supervisor suggested a Diagnostic Center that would teach and observe the children for several weeks as the best option for a thorough evaluation. The Diagnostic Center was suggested at the first meeting with the school, but the school objected saying there was at least a three-month wait to get children into the Center. After this meeting, the student attorney, convinced that the Diagnostic Center was the only option likely to result in a meaningful evaluation for these two 5-year-old boys, went in person to the Center 
and presented the facts about the two boys to the Center Director. The director agreed to come and see the boys at their school. They were accepted into the program almost immediately. They spent six weeks in this highly structured, supportive setting and were very responsive to the structure offered there. Thorough evaluations of each child were done by staff pediatricians and psychologists and provided to the school.

Upon their return to school, the boys were placed in the same class (as recommended by the Center) and the various methods for reinforcing good bebavior used by the Center were employed in their regular classroom. The transition back to their bome school went very smoothly (to everyone's surprise). By the end of the school year, they were voted the "most improved" students in the entire school.

The student attorney followed up with the school to make sure an appropriate IEP was put in place for each child by the school for next year. The student social worker made sure our client followed up with recommendations made by the Center for therapy for the boys.

Having a student social worker and a student attorney made a big difference for this family. Probably the most significant contribution the student attorney and her supervisor made was to recognize the value of the Diagnostic Center to these boys, and to pursue it vigorously on their behalf. The student attorney's sense of responsibility for the outcome and zealous advocacy on behalf of these boys made a big difference. On the other hand, the student social worker was able to work with the client to manage the boys at home, get them into a bedtime routine, etc., which also contributed significantly to their improved behavior at school.

\section{Social Workers Identify Systemic Problems and Bring in Lawyers to Search for Remedy}

\section{Case Example \#4}

The grandmother was raising ber 11-year-old granddaughter. The family was living in a very poor bousing situation and needed income to belp with relocation. The grandmother applied to the Department of Social Services for temporary cash assistance, but was told she would need to engage in a work activity to qualify for more than a child-only grant. The student attorney and student social worker questioned this decision because it seemed unfair that an indigent grandmother who stepped in to care for ber grandchild would bave to enter a work program to qualify for benefits.

The student attorney checked regulations and found that an exemption in fact existed for indigent relative caregivers. She gave this information to the student social worker who returned to the DSS office and successfully belped the grandmother qualify for benefits. ${ }^{16}$ The student social worker was then able to assist the grandmother in finding better bousing.

16 A major role that student attorneys play in this partnership is to assist grandparents in seeking legal custody. Most grandparents caring for grandchildren in Baltimore City do not have legal custody, even though they may have been caring for children for years. In most cases the petition is not contested by either parent, so these cases should be quite simple. In theory, grandparents should be able to file on their own, and a few do. However, despite the availability of pro se forms at the courthouse, barriers still exist to pro se filing. For example, grandparents must give the court an address for an absent parent. If no address is listed, the court clerk will refuse to file the petition. No explanation of how to pursue alternative service is given to grandparents. In addition, the process to obtain a fee waiver is not user friendly. 
We plan to meet with the DSS to be sure all workers are informed of this rule. Armed with this regulation, our social work partners can continue to assist indigent grandparent caregivers in qualifying for full benefits, without the imposition of a work requirement.

Social Workers Can Help Clients Sort Out Feelings to be Sure They Are Making the Best Decision for Themselves and Their Grandchildren Before Legal Action is Initiated

Case Example \#5

The grandmother/client said she wished to pursue adoption of her 6-year-old granddaughter, whom she had cared for since birth. The child was born with serious medical needs requiring intensive 24-bour care. The child's young parents were not able to provide the care she needed. The grandmother was very angry at her son for not taking responsibility for his daugbter, and seemed to think that ber adoption of the child would teach bim a lesson. At the same time, bowever, she talked about boping that her son would eventually step in to take responsibility for bis daughter, when she no longer might be able to care for her.

We counseled the grandmother about the consequences of adoption, pro and con, and also about the alternative of seeking legal custody. However, she insisted that she wanted to proceed with adoption, even if it would mean terminating ber son's parental rights.

Ultimately, it was the social work student who was best able to belp the client separate out her anger at her son from what was best for her granddaugbter. The client decided instead to flle for permanent custody, leaving open the possibility that her son could eventually step in.

Student attorneys learned that a client's stated goal may change given time for reflection and more thought about the consequences of the choice.

\section{BENEFITS FOR STUDENT SOCIAL WORKERS AND STUDENT ATTORNEYS OF INTERDISCIPLINARY PRACTICE}

Law clinics have already borrowed approaches to client counseling from social workers - e.g., the idea of client-centered decision making. But law students can gain additional insights from working with student social workers. For example, social work students help law students understand the notion of client engagement. Social work students understand the effort it may take, over a long period of time, to truly connect with a client. And that engagement can be achieved and then lost, when other more pressing needs arise in the client's life. Student attorneys tend to become very frustrated with clients who do not follow through, fail to show for appointments, etc. Student social

Our long-term goal is to address these issues of access. However, some grandparents are so overwhelmed with their caregiving responsibilities that they would still have a difficult time dealing with this process. This is another area where student attorneys can be very helpful by drafting the necessary documents and presenting these cases to the Court. It also provides student attorneys with a great opportunity to present a case, including a brief argument and witness examination before the Court. 
workers are able to help them see this in the context of the clients' lives overall. Student social workers often must be very persistent to get clients engaged in the program.

Our collaboration brings to the forefront interesting differences between how lawyers and social workers are trained. Lawyers are taught and encouraged to assume responsibility for the client's problem. Social workers, on the other hand, are taught not to assume this responsibility. The social worker can and should provide assistance, but the problem remains the client's to solve. The social worker's goal is to work with the client/family to enable them to solve problems themselves.

Interestingly, empowerment is often cited as a primary goal by lawyers for the poor. ${ }^{17}$ This goal seems to be significantly difficult for lawyers to achieve, however, in part perhaps because of training lawyers receive about the need to be in charge and responsible. One of the great benefits of our joint practice has been that we have been reminded of this goal of empowerment and forced to review how our work with clients does or does not try to meet this goal.

One problem is that the goal of client empowerment sometimes gets lost in the rush to get things done. The sheer volume of cases also tends to pressure the lawyer to deal with cases and clients as quickly and efficiently as possible. Even worse, the press of too many cases and the goal of achieving a concrete result sometimes results in the lawyer's failure to communicate effectively with the client to truly understand the client's goals for the case. In our joint practice, our social work partners remind us of the importance of practicing in such a way that clients are empowered and fully involved in their cases.

A primary goal of clinical education is to give students the opportunity to try on their new "lawyer" role. How do they define themselves in their new role? What are the limits of the role? How does being a lawyer for a client differ from being the client's social worker? What is a lawyer's responsibility when she fears the client is about to make a poor decision? Is the answer the same for lawyers as for social workers? What should a lawyer or social worker do when a client calls just to talk? Is the response the same or different, depending on the role?

Collaborating with a student social worker in some ways can make this process of role definition more confusing initially, but ultimately with facilitated discussion and reflection, it leads to a deeper understanding of what role a lawyer can play and the limits of his or her role.

One positive outcome of working as full partners is that the student attorneys and student social workers tend to develop a much deeper understanding and appreciation for the other's profession. This is particularly true for student attorneys, who in some clinical settings have been accused of arrogance and a lack of understanding of and appreciation for social workers assisting with legal cases. ${ }^{18}$ In practice together, they are able to overcome stereotypes and gain a better understanding of each other's goals and skills.

17 The hallmark of an effective poor people's practice is that the lawyer does not do anything for his clients that they can do or be taught to do for themselves. Stephen Wexler, Practicing Law for Poor People, 79 YALE L.J. 1049, 1055.

18 Toby Golick \& Janet Lessen, A Law and Social Work Clinical Program for the Elderly and Disabled: Past and Future Challenges, 14 Journal OF LAw AND POLICY 183 (2004). 
Although social work students and student lawyers have developed positive relationships of mutual respect in both programs, when social work services are seen as support to the legal case, there is sometimes a danger that the law students perceive these services as subordinate, and therefore less important. In the GFC model, where students worked truly as partners, students tended to gain a greater appreciation and understanding for the work of their social work colleagues.

Having this knowledge and respect for each other from their joint practice experience will be particularly valuable for students entering areas of practice where lawyers and social workers routinely work side by side, for example, in family law, elder law, and particularly in child welfare cases.

Another benefit of collaborative practice for student attorneys is the sense of partnership in working with clients. Students in Law Clinic are out there on their own with clients with overwhelming problems, with the ability to address only a fraction of the needs, as frequently occurs in legal services practice. In our joint practice, the social work partner is available to help meet immediate concrete needs, e.g., helping a client apply for benefits. In the meantime, the student attorney can move ahead with drafting a custody petition. The student social worker appreciates that the legal resolution of the custody issue will make seeking benefits easier for the client in the future.

\section{ADDRESSING DIFFERENT ETHICAL RULES GOVERNING SOCIAL WORKERS AND LAWYERS}

The interdisciplinary practice described in this article is a collaboration of professionals. We were clear from the beginning that because we wished to work collaboratively as equals, no one profession would be in charge, and therefore no one set of professional rules could govern. To address the issues this could create, we spent planning time anticipating conflicts that could arise and developing a plan for how we would respond.

Among the potential barriers to interdisciplinary practice we identified initially were rules of professional conduct for attorneys that prohibited certain forms of joint practice; concerns about the different ways lawyers, social workers, and medical providers define client or patient; concerns about social workers and medical providers being mandatory reporters of suspected child abuse or neglect; and concerns generally abour confidentiality obligations and the impact of our joint practice on the attorney/client privilege. Social workers had concerns about the tendency of lawyers to dominate situations and lawyers' often adversarial approach to cases. Below, I describe how we experienced each of these issues and thoughts about how each can be addressed in a truly interdisciplinary practice.

\section{Concerns About Professional Independence}

One of the first issues we addressed was how the rules about the importance of lawyers' maintaining their professional independence would impact our planned collaborative practice. In this connection, we reviewed Md. Rule 5.4 and the ABA Model Rule. 
The primary focus of Md. Rule 5.4, and the very similar ABA Model Rule of Professional Conduct, is on the dangers inherent in lawyers sharing legal fees or profits with a non-lawyer. For example, Md. Rule 5.4 (a) begins, "A lawyer or law firm shall not share legal fees with a non-lawyer," subject to certain exceptions. And "(d) A lawyer shall not practice with or in the form of a professional corporation or association authorized to practice law for a profit, if: ... (3) a non-lawyer has the right to direct or control the professional judgment of a lawyer."

But Rule 5.4(a)(5) also provides that "a lawyer may share court-awarded legal fees with a nonprofit organization that employed, retained or recommended employment of the lawyer in the matter."

After discussion and consultation, we concluded that these Rules were not intended to prohibit the collaborative practice we proposed to undertake. First of all, we would not be practicing law for a profit. We would not be sharing legal fees with a non-lawyer. In addition, a non-lawyer would not have the right to direct or control the professional judgment of a lawyer.

Although we would consult with our collaborators and give their opinions appropriate consideration, ultimate decisions on whether to take on a particular legal matter and how to conduct the case would remain the province of the lawyer in consultation with the client. ${ }^{19}$

But a lingering doubt remained. Even if our work would not technically violate professional rules, would such close collaboration with social workers exert some influence on our legal representation of clients that would in some way interfere with our judgment, or harm the client?

Simply being aware of the question made us vigilant to observe what took place in our day-to-day collaboration. Certainly the nature of a collaborative practice is that we often influence each other's perception of the client and the case. We educate each other about the client's legal and psycho-social issues. We share impressions of the client and often arrive at a more complete understanding of the client's needs and motivations.

One answer to this concern about independence of judgment would be simply to conclude that judgment is intended to govern the legal aspects of a situation-e.g., what information to include in a petition for custody, what witnesses to call, etc. It can be argued that there is no value in a lawyer's maintaining independence of judgment about issues outside his or her expertise-e.g., whether a child needs in-patient mental health treatment. Clearly it is necessary and appropriate to look to an expert for this type of opinion.

However, upon further reflection, we realized it could be argued that to be able to exercise completely independent judgment, the lawyer must be knowledgeable and educated about the judgments the social worker will be making. The lawyer must know enough to raise questions where appropriate. An analogy could perhaps be made to a lawyer's preparing to cross-examine an expert witness. The lawyer must be sufficiently

19 See MD Rule of Professional Conduct 2.1. 
knowledgeable to ask probing questions to challenge the underpinnings of the expert's opinion. $^{20}$

So in our joint practice, we set aside time to have in-depth discussions of the various issues facing each client, and the role that each of us would play in trying to assist the client. We did not simply accept a social work recommendation of a particular course of action without fully understanding the reasoning behind the recommendation. Often we would influence each other and the client about the appropriate course to take.

We found that rather than social workers inappropriately influencing lawyer judgment, it was more likely that the lawyers will be tempted to direct the social workers in getting things done. Lawyers tend to be more goal-directed and driven to accomplish concrete objectives. For example, the lawyer may want to go ahead and get the custody petition filed so the grandchildren involved will have some protection. The social worker may feel that the grandmother is not really ready to make that commitment and needs more time to decide how to proceed. In this situation, the decision about how to proceed is left to the client, after both the lawyer and social worker have assisted her in identifying the pros and cons of moving ahead or waiting.

The primary area we have observed where zealous advocacy might be rempered somewhat is in the area of intra-familial disputes. But this tempering is often appropriate to the nature of the dispute, as pointed out by advocates for therapeutic jurisprudence. ${ }^{21}$

The purpose of a custody proceeding is to find what outcome is in the best interest of the child. We are mindful of that goal in representing our grandparent clients.

Social workers' focus on client empowerment has had a positive impact on our representation. It forced us as lawyers who believe in client-centered decision making to slow down and think through whether our actions on behalf of our clients were achieving the goal of client empowerment. Were we really deferring to the client's wishes? Were we taking sufficient time to explain our actions and court processes, etc., to our clients? What actions can or should we take to be sure the client is in a stronger, more knowledgeable position when we close her case?

\section{Who is the Client?}

One of the difficult questions we faced in planning this collaborative practice was defining who the client is. This can be a difficult issue even for lawyers practicing alone, ${ }^{22}$ but it is made more complex by the addition of social work collaborators. Our social work partners in this setting tended to see the family as their client. Part of their goal was often

20 There is an increasing recognition that legal education alone does not give lawyers the expertise they need to deliver quality representation. For example, the family court system increasingly recognizes that to be effective in their representation of clients, lawyers in family cases need education beyond knowledge of family law. Maryland recently enacted an Appendix to the Rules of Professional Conduct encouraging lawyers representing children in "Child in Need of Assistance" cases to take steps to educate themselves about child development, family dynamics, and dysfunction, including substance abuse and mental illness.

21 See Law in a Therapeutic Key: Developments in Therapeutic Jurisprudence, (David B. Wexler \& Bruce J. Winick eds., 1996). See also David Luban, The Adversary System Excuse, The Good Lawyer, 83 (1984).

22 E.g., special education cases, impact of representation in family cases with children. 
to work with the family to address issues to improve the functioning of the family system. Though their focus was supporting grandparent families, this would sometimes involve meeting with and working with other family members, e.g., parents of the children who were living in their grandparent's care.

Our goal also was to provide support to the family as a whole, but the lawyers had to be aware of conflict-of-interest rules that could impact our ability to offer assistance to family members. Generally speaking, we defined the client as the grandparent and were careful not to take steps that could impede our ability to assist that client.

Interestingly, so far it has worked out to define the client slightly differently. Again, the key is to identify this issue up front and be clear about how the interdisciplinary team is addressing it. ${ }^{23}$

However, the lawyers continue to have to be thoughtful about contact with extended family members. For example, sometimes a student social worker working with a family will invite a student attorney to a meeting with a grandmother and morher in order to discuss how custody should be resolved. Although the student attorney would be glad to assist them in reaching agreement as to custody, the student attorney must be aware of the consequences of this involvement. If the student attends the meeting without clearly identifying who she represents, the lawyers may be later be precluded from representing anyone if a conflict should arise.

The lawyers sometimes do not have sufficient information to decide if pursuing custody on behalf of the grandparent is feasible or advisable. In other situations, e.g., where the children have been with the grandparent for many years and have spent very little time with the parent, we may feel that representing the grandparent in a petition for custody is a likely outcome. However, if we attend the meeting with the parent as lawyer for the grandmother, this may introduce an adversarial tone. Sometimes the grandparent will express her feeling that bringing in a lawyer will make the situation more difficult. In these cases, we will not participate and leave it to the social worker to see if the parties are able to reach an agreement on their own. Then we are free either to step in later to help formalize the agreement that has been reached or to pursue a custody petition on behalf of the grandparent if appropriate.

\section{Abuse and Neglect Reporting}

Another area of potential conflict arises because social workers must report any child abuse or neglect that they observed or have reason to believe is occurring. ${ }^{24}$ Lawyers on the other hand, are generally required by confidentiality rules to protect their clients'

23 A related ethical concern that has come up in theory, though not in practice, is that the social worker in her meeting with parent and grandparent might obtain adverse information from the parent in the course of their discussion. If the situation was later to become an adversarial custody dispute, would there be any problem with (the lawyers) using this information against the parent? If we had been present for the conversation, unless we clearly identified ourselves as counsel for grandmother, we would be precluded from using this information. Are we one practice or two separate practices working in collaboration? In fact, social workers do enter into contract with the grandparent, not with the entire family.

24 Md. Code Ann. Family Law \$5-704 (2007). 
confidences and have discretion to report only if they are concerned about a future risk of serious physical harm. ${ }^{25}$

Often when social workers are employed in law offices, the lawyers take the position that the social workers, as employees of the law office, are bound by the lawyers' rules of professional conduct, and therefore cannot abide by the usual mandate that social workers must report any suspected abuse or neglect.

However, this reliance on the idea that social workers are employees of the law office, similar to administrative staff or paralegals, does not take into account that social workers are professionals with their own legally mandated obligations.

Depending on the type of practice, social workers may contest the conclusion that their statutorily mandated reporting requirement must give way to the lawyer's obligation to protect her client's confidentiality, and feel that their professional obligation cannot be so easily dismissed.

In Maryland, a 1990 Attorney General's opinion concluded that social workers working in law offices are in fact still bound by their reporting responsibilities, unless the client they are working with has been criminally charged. ${ }^{26}$

As a result, in the clinical practice that predated the GFC collaboration, the AIDS Legal Clinic was already compelled to consider this issue when deciding whether to refer a client to our social work program. We would discuss the available services with the client and explain the reporting obligation. If clients wished to receive services, which they typically did, we would ask them to sign a consent form acknowledging that the reporting issue had been explained to them.

In addressing this question, the District of Columbia Bar Association Ethics Committee at first concluded that a social worker employed by a law firm is bound by the confidentiality rules governing lawyers. However, the opinion then goes on to say that "the Rules of Professional Conduct cannot insulate a social worker from obligations otherwise imposed by law," but later acknowledges that it is arguable that the social worker has no reporting obligation in this circumstance. Ultimately, the advice offered

25 Rule 1.6 of the Maryland Rules of Professional Conduct provides that: (a) A lawyer shall not reveal information relating to representation of a client unless the client gives informed consent, the disclosure is impliedly authorized in order to carry out the representation, or the disclosure is permitted by paragraph (b); (b) A lawyer may reveal information relating to the representation of a client to the extent the lawyer reasonably believes necessary: (1) to prevent reasonably certain death or substantial bodily harm.

26 In his Opinion (Opinions of the Attorney General, 1990, Opinion No. 90-007) dated 2/8/1990, Maryland Attorney General J. Joseph Curran, Jr. concluded that the only exception to the requirement of a mental health care worker to report child abuse or neglect is if they learn of the abuse or neglect from a client, referred by an attorney as part of the attorney's trial preparation, after the initial criminal proceeding against the client. In this case, the social worker is covered by the attorney's confidentiality. This exception is very narrowly defined in that it is only applicable if the social worker is working with a client who has already been charged and is referred by the attorney to assist in preparation of the client's defense (i.e., perhaps to identify appropriate treatment alternatives). As our social work collaborators felt very strongly that their reporting obligation could not be alleviaced by the argument that they were working as employees in our law office (a viewpoint that the Attorney General's opinion vindicated), the following compromise was agreed to. Before any client is referred to the Law Clinic's social work component they must be informed about the social work reporting obligation and given the option to decline services. As a practical matter, this compromise has meant that there are times when we simply do not refer cases to social work because of a concern about this reporting obligation. This has the unfortunate result that sometimes the clients most in need of these services (typically those involved in CINA cases) do not receive them. 
was for lawyers and social workers in this situation to warn clients that the social worker may have a statutory obligation to report suspected abuse revealed by the client. ${ }^{27}$

In the GFC project, where social workers and attorneys agreed to enter the project as equals, we were compelled to address this potential conflict in a slightly different way. The easy case would be the situation where we all agreed that a child was at imminent risk of serious bodily injury, and we could all agree that a report was appropriate. The more difficult question would be about abuse that had occurred in the past or neglect of a less serious nature where a lawyer would definitely not breach confidentiality, and a social worker would be mandated to report.

We resolved this conflict of rules by deciding we would each abide by our own professional rules, and not try to impose these on each other. Thus, if a client made a disclosure to the social worker, the social worker would follow his or her usual procedures regarding disclosure. The social worker could bring her concern to the Team for discussion before making a report but was not required to do so if time was of the essence. If a disclosure was made to the lawyer, the lawyer would not have a reporting obligation. $\mathrm{He}$ or she would, however, bring the information to the social workers' attention if it appeared to be relevant to any current risk to the child.

Importantly, all clients are informed up front about the social work reporting obligation, and about the fact that the lawyers, social workers, and nurses are working collaboratively and sharing information. Clients sign a release when they enter the program consenting to the sharing of information among the three entities and acknowledging the reporting obligation. If they do not wish to sign the consent, they are not eligible for services in this program. ${ }^{28}$

In the three years of the program's operation, we have on several occasions discussed whether the information we had all received required reporting by the social workers, but only three reports were made. The Department of Social Services did not find it necessary to remove the children in any of these cases because it was aware that Grandparent Family Connections social workers were working with the families to address the issues that led to the report.

The bottom line is that with advance planning and mutual understanding and trust, including notice to and consent from clients, the social work reporting obligation does not have to be the impediment to joint practice that it has been in the past. Difficult situations do arise at times, but with advance planning they can be appropriately addressed.

27 District of Columbia Bar Association Ethics Op. 282 (1998).

28 I agree with Anderson, Barenburg, and Tremblay when they conclude that lawyering is often more effective when done in collaboration with other professionals, e.g., social workers. However, their conclusion that the best way to address differences in reporting obligations is to place the social worker within a law firm is unduly limiting. Alexis Anderson, Lynn Barenburg, \& Paul Tremblay, Professional Ethics in Interdisciplinary Collaboratives, Zeal, Paternalism and Mandated Reporting, 13 CliniCal L. Rev., 659-718 (2007). 


\section{CONCLUSION}

Although the long-term impact on grandparent families of this interdisciplinary intervention remains to be seen, in the short term there is no question that has been very successful. The combination of six months of social work and legal services has resulted in improved stability for the families we worked with.

Clients who worked with both a student social worker and a student attorney tended, not surprisingly, to develop a deeper connection to and appreciation of the Grandparent Family Connections program. This is demonstrated in part by their willingness to respond to periodic surveys from Grandparent Family Connections after services to the family have ended.

This joint education of student attorneys and student social workers in a clinical experience enhanced their understanding of their roles and of the other profession. It also prepared each group of students for a more thoughtful and informed approach to family law, child welfare cases, working with children with special needs, and assisting families in pursuing public benefits. This is an opportunity that should not be overlooked. 